\title{
A Stochastic Dynamic Programming Model for Valuing a Eucalyptus Investment
}

\author{
M. Ricardo Cunha ${ }^{1}$ and Dalila B. M. M. Fontes ${ }^{2}$ \\ ${ }^{1}$ Universidade Católica Portuguesa and Lancaster University \\ Faculdade de Economia e Gestão \\ R. Diogo Botelho, 1327 4169-005 Porto, Portugal. \\ mrcunha@porto.ucp.pt \\ ${ }^{2}$ Faculdade de Economia da Universidade do Porto and LIAAD - INESC Porto L. A. \\ Rua Dr. Roberto Frias, 4200-464 Porto, Portugal. \\ fontes@fep.up.pt
}

\section{Abstract}

This work proposes an exercise-dependent real options model for the valuation and optimal harvest timing of a forestry investment in eucalyptus. Investment in eucalyptus is complex, as trees allow for two cuts without re-plantation, and have a specific time and growth window in which they are suitable for industrial processing into paper pulp. Thus, path dependency in the cutting options is observed, since the moment of exercise of the first option determines the time interval in which the second option may be exercised. Therefore, the value of the second option depends on the history of the state variables rather than on its final value. In addition, the options to abandon the project, or convert land to another use, are also considered. The option value is estimated by solving a stochastic dynamic programming model. Results are reported for a case study in the Portuguese eucalyptus forest which show that price uncertainty postpones the optimal cutting decisions. Moreover, optimal harvesting policies deviate from present practice of forest managers and allow for considerable gains.

Key words. Real Options, Dynamic Programming, Forestry Investments, Binomial Lattice.

\section{Introduction}

Traditionally, forestry investment decisions were analyzed by using Discounted Cash Flow (DCF) techniques. Given their inability to account for flexibility, these approaches tend to systematically undervalue investments. DCF techniques are based on the assumption that future cash flows follow a constant pattern and can be accurately predicted. The project uncertainty, which may arise from the uncertainty about costs, selling prices, weather and legal conditions, to name but a few, 


\section{ADVANCES IN MODELING AGRICULTURAL SYSTEMS}

and the flexibility, given to managers to react to changing conditions, are dealt with only superficially [20]. Another disadvantage of DCF is that it is linear and static in nature. It also assumes the project to be either irreversible or if reversible only decisions of now-or-never are allowed [10]. In particular, net Present Value (NPV) takes the project risk into consideration by discounting expected cash flows to the present moment. This discount considers risk either by using certaintyequivalent cash flows [24], or by discounting cash flows using a risk adjusted discount rate that can be obtained either through the use of the capital asset pricing model [25] or from a comparison with the market return rates of "similar or risk equivalent" investments. This last approach is the most generalized among practitioners. Using this decision process, all projects with positive NPV are undertaken, as they provide an "effective" growth in the wealth of the investor (or market value of the firm). Forest investors, namely paper pulp production companies, use the NPV to decide whether to enter or not a specific investment project. The NPV technique, by not accounting for managerial flexibility, provides an underestimate of the project value, relative to real options. Therefore, when there is an option element in an investment, traditional DCF techniques may result in wrong project valuation and hence inadequate decisions, see e.g., [21] and [10].

Although the writings of Aristotle in Ancient Greece already mention the existence of such features in business and investment, only in the seventies applications to natural resources management have been known [14,3]. Many other researchers have treated the question of replacing a forest stand with the same or other land use, the value of both being stochastic, e.g. [30], [23] and [1].

In a real options model of forestry, and particularly in eucalyptus, the basis starting point is that the owner of the forest holds a call option ${ }^{1}$, i.e., an option to acquire timber at an exercise price given by the cost of cutting the timber. This forestry option is similar to what in the finance literature is called an American option, since it can be exercised at any moment within the time interval during which the wood is suitable for pulp and paper production. Traditionally, studies addressing real options in a forest context have applied a single option approach [18]. Such studies are however not suitable for the valuation of multiple harvesting forestry investments, as investments in eucalyptus. Our study goes consequently beyond previous studies by considering two cutting options, with potential extensions. Therefore, we have to decide when to harvest having in mind that a second harvest is possible and also that the latter must occur within a time window dependent on when the previous harvest has taken place. Unlike the single rotation problem, the multirotation case represents a path dependent option, which is far more complex, see [28]. In this case, the option value depends also on the history

\footnotetext{
${ }^{1}$ An option is the right, but not the obligation, to take some action in the future under specified terms. A call option gives the holder the right to buy a stock at a specified future date (maturity) by a specified price (exercise or strike price). This option will be exercised (used) if the stock price on that date exceeds the exercise price.
} 
of the underlying state variables rather than only on their final value. Therefore, the project value today depends on the quantity of timber, which in turn depends on the timing of the previous harvest. In addition, we also consider the options to convert land usage and abandon project.

Results are provided for a case study involving the investment in eucalyptus pulp production for the Portuguese paper industry, one of the most developed in the world. In this case study, two scenarios are considered: one where eucalyptus wood is sold to pulp and paper companies (base problem) and another where vertical integration is considered, i.e., wood is processed into white paper pulpwood, which is then sold (extended problem).

After determining the maximum expected value of the investment, we retrieve the policy associated with such a value. Then, in order to test the quality of the cutting strategy and its robustness, we apply the strategies obtained to randomly generated data and compare the values obtained with the current practice of forest managers.

\section{Literature Review}

In 1973 for the first time, Black \& Scholes [5] and Merton [19] provided a closed form solution for the equilibrium price of a call option, leading to a new paradigm in asset valuation. The model they developed gave origin to numerous papers and empirical research in contingent claims analysis, and to applications to many types of contingent claims. Among these, valuation models for real investments have appeared, giving birth to the real options theory of investment decisions.

To this date, not many studies have addressed forestry investments using a real options perspective and, as far as the authors are aware of, no previous work has been developed in what concerns investment in eucalyptus forests. Morck et al. [20] developed a contingent claims analysis of a long-term investment in renewable resource investments. They have extended the general model of valuation of natural resources developed for a gold mining application [6]. Their model values a forestry lease and determines the optimal timing to harvest the timber. The value of the lease is considered to be the value of an option to cut down the trees at the best possible timing. In their model the timber selling price and the inventory of timber are stochastic processes that follow geometric brownian motions. Zinkhan [30] proposes a Black-Scholes type of approach for the valuation of the land use conversion option when valuing timberlands. The conversion option represents the ability of the timberland owner to convert the land use from timber to some other alternative use. Thomson [26] develops this model further in an attempt to increase its consistency and simplicity. In both works it is assumed that the land owner holds a European option rather than an American one. Bailey [4] proposes a model to value an agricultural producer considering optimal shutting and reopening and volatile output and demand. However, in what concerns forestry, the model is built only for productive trees with periodical (e.g., annual) harvest. This 


\section{ADVANCES IN MODELING AGRICULTURAL SYSTEMS}

characteristic of the model makes it useless for our purpose of valuation of forestry investment in eucalyptus for paper pulp production, where after two cuts the asset is "worthless" for the paper industry. Abildtrup \& Strange [1] analyze the decision to convert a natural or semi-natural forest into Christmas tree production, when groundwater contamination is irreversible and future returns on noncontaminated groundwater resources and Christmas tree production are uncertain. These authors concluded that conventional expected NPV analysis may not lead to an optimal decision rule, and show that the option to postpone conversion and acquire new information should be included. Yin [29] discusses harvest timing, land acquisition, and entry decisions combining forest level analysis and options valuation approach. Other authors have studied the impact of assuming that stochastic prices follow a mean reverting process rather than geometric brownian motion, see e.g., [16] and [13].

Most of the studies addressing real options in the forest investment context have applied a single option approach. However, exceptions can be found in the literature. Some authors consider additional problem features, while others consider more than a single option. For example, Malchow-Mollera et al. [18] include temporal and spatial arrangement of harvests. These authors consider that constraints upon harvesting options on adjacent forest stands are imposed and examine the optimal harvest rules under adjacency restrictions and uncertainty. They conclude that the costs of adjacency constraints tend to increase with uncertainty and that the optimal harvesting strategies become rather complex due to the interaction of the involved stochastic variables. Duku-Kaakyire \& Nanang [11] developed a forestry investment analysis where four management options are considered: delay of reforestation, capacity expansion, investment abandonment, and a compound option obtained considering simultaneously all three previous options. The models developed are valued on a standard binomial lattice. The authors solve an example with which they show that DCF techniques value the investment as unprofitable, consequently rejecting it. Real options, however, show the investment to be highly valuable. Insley \& Rollins [16] model the harvesting problem assuming infinite rotations as a linear complementarity problem that was solved numerically. The accuracy of the solution, obviously, depends on the grid used. Given the computational experiments performed the authors were able to conclude that the value of the harvesting option can be very sensitive to the number of discrete levels of the stochastic variable.

In this work, the main objective is to develop a methodology that allows for the valuation of the investment in eucalyptus forest and also to find an optimal harvesting policy, considering the managerial flexibility inherent to the process. Although a similar problem to that of Insley \& Rollins [16] is addressed, their methodology cannot be applied to eucalyptus forestry investments, since they consider an infinite time horizon framework. Furthermore, this study goes beyond the usual valuation approach since the harvesting policies found are tested by being reapplied to specific data, both real and random. 


\section{Problem Description}

The investment decision under consideration includes three main options: the option to cut down the trees; the option to postpone or defer the trees harvesting until the price or quantity is favorable; and the option to convert the land to another use or to abandon the project. We model and solve the problem by considering a compound option obtained by considering all the aforementioned options simultaneously. It should be noticed that the decision of when to harvest the trees is associated with both harvesting options (cut and postponement). Furthermore, these decisions and thus options, must be taken twice since the eucalyptus globulous plantations allows for two rotations without replantation.

Many variables guide the profitability of the investment in eucalyptus. Nature, for example, has a major role in the growth of trees. Therefore, the inventory of timber is a very important decision factor. In this work timber inventory is considered to follow a deterministic process with a known growth pattern depending on the region under consideration, the time since last cut (or plantation), and rotation. Also, an obviously very important factor for the decision making is the paper pulpwood selling price, since it determines the main positive cash flow. This price is stochastic and it is assumed to follow a geometric brownian motion. This is further discussed in Section 1.

\section{The investment decisions}

During the investment process in forestry, and particularly in eucalyptus, when the tree is mature, the landowner possesses the option to cut down the trees and receive the resulting cash flow. On the other hand, such a decision may be postponed if price and/or wood inventory conditions are not favorable. This option is similar to a financial option on a stock, where the underlying asset is the amount of wood in the land and the strike price is the cost of cutting the trees and logging the wood. However, as previously explained, the investment process in eucalyptus is normally composed of two rotations (production cycles). The trees planted at the beginning of the process are suitable for two cuts - after the first cut trees regrow, permitting a second cut without replantation. Regarding the timing of cut, the characteristics of the wood that could be extracted from trees which are up to 7 years old do not fit the requirements of the industrial producers of pulpwood. The same happens after 16 years of growth, when the diameter of the trees becomes too large for its industrial processing and the fiber in the wood is not of the required standards. Thus, the window time frame is 9 years, for both rotations. However, as the time of exercise of the first option determines the time window during which the second option may be exercised, its temporal location depends on the timing of the first cut. Furthermore, the total expected payoff to be received is given by the sum of the first and second harvesting expected cash flows. Given the path dependency observed, the cash flow received from the second harvesting depends upon the timing of the first harvesting. This dependency leads to a multi- 


\section{ADVANCES IN MODELING AGRICULTURAL SYSTEMS}

plicity of possible paths and strategies, as can be seen in the state transition diagram given in Figure 1. In this diagram we have represented the time $t$ and the elapsed time since last cut or plantation $x_{t}$, with a 2-years step interval.

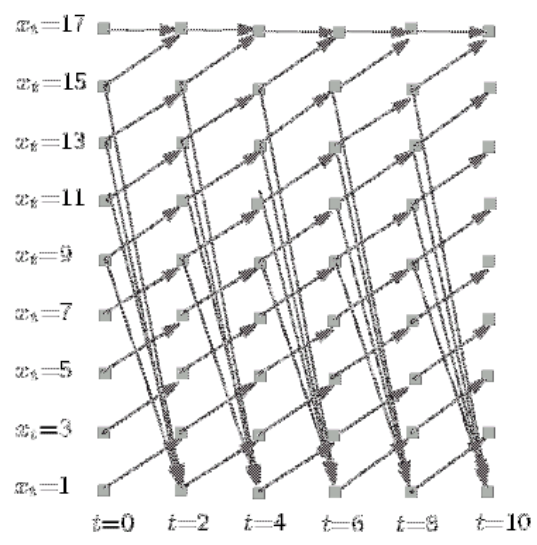

Figure 1: State transition diagram: 2-years step interval.

The cash flow to be received from harvesting the trees depends on the cutting period - since the quantity of wood, although known, evolves through time - and on wood market price and future value expectations. Moreover, the decision of cutting the trees in the first rotation must consider not only the immediate cash flow, but also the expectation of the cash flow from the second rotation.

In our analysis, the eucalyptus forest investor is assumed to hold the land. Therefore, at any moment in time the investor holds the option to abandon the project and put it aside, or receive an estimated value from converting the land into an alternative use. Activities like tourism and hunting have increased the demand for forest land and hence, its value. This alternative value (or capacity to abandon without a loss greater than the initial land acquisition investment) must then be considered in the valuation of eucalyptus forest investment.

\section{Methodology}

The approach developed consists of a dynamic programming model which is evaluated on a discrete-valued lattice. The uncertainty of the underlying risky asset, wood or paper pulp selling price, is modeled through the use of a standard binomial lattice. This approach is described in the following section. To develop the dynamic programming model, we first must define and explain the decision variables as well as the state variables. The decision variables are associated with the possible strategic decisions that investors and managers may undertake during the investment process, while the state variables are related to time, see Section 2. In Section 3 we present the dynamic programming model and explain how to solve it 
through backward induction. The optimal value of the investment project and the corresponding optimal harvesting strategy are given by the solutions to the proposed model.

\subsection{The binomial lattice}

The analysis performed in this work makes use of the multiplicative binomial model of Cox, Ross \& Rubinstein [8], the standard tool for option-pricing in discrete time. In this approach, the stochastic variable (the selling price in our case) is assumed to be governed by a geometric diffusion, which implies that at each period there is only one constant growth/decay rate. If this is assumed, a natural way of obtaining a valued-lattice for the stochastic variable is to discretize it through a standard binomial lattice, see Figure 2.

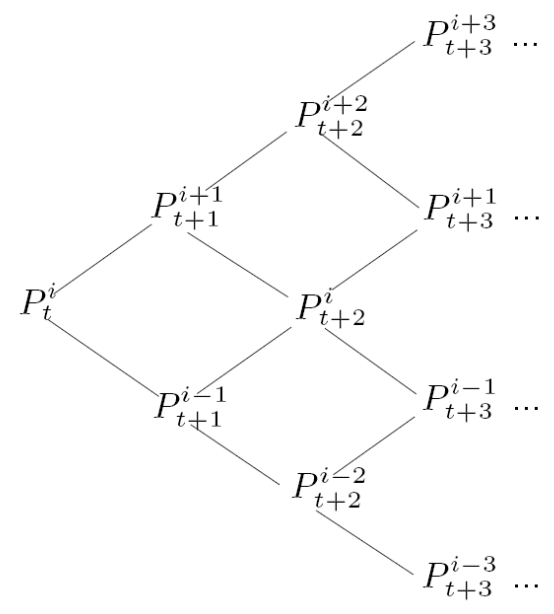

Figure 2. A lattice discretizing selling price.

A node of price value $P_{t}^{i}$ can lead to two nodes with their values being given by $P_{t+1}^{i+1}=u P_{t}^{i}$ and $P_{t+1}^{i-1}=d P_{t}^{i}$ with probability $p$ and $q=1-p$, respectively. The probability of reaching each of these nodes is the usual equivalent martingale measure used in the binomial option pricing model of Cox et al. (1979):

$$
p=\frac{\left(1+r_{f}\right)-d}{u-d} \text { and } q=1-p
$$

where $r_{f}$ is the risk free interest rate over the interval $\Delta t, u=\exp (\sigma \sqrt{\Delta t})$, $d=\exp (-\sigma \sqrt{\Delta t})$, and $\sigma$ is the standard deviation. It should be noticed that, 


\section{ADVANCES IN MODELING AGRICULTURAL SYSTEMS}

as $\Delta t \rightarrow 0$ the parameters of the multiplicative binomial process converge to the geometric brownian motion.

The advantages of this approach are that (i) it can be used to price options other than European, like American and path dependent options; (ii) it does not depend on the investor subject probabilities of an upward/downward price movement, since it uses risk neutral probabilities; and (iii) it is intuitive and simple to understand and implement.

The binomial model breaks down the investment horizon into $n$ time intervals or steps. The lattice is then developed in a forward movement by finding the value of selling prices. At each step the price moves up or down by an amount obtained from its volatility, which is assumed to be constant and known, and the time step length. Thus, the lattice provides a representation of possible selling prices throughout the whole project life.

\subsection{Decision and state variables}

The selling price variable $P_{t}^{i}$ is modeled as a stochastic variable, which follows a binomial process, as in the previous section.

In terms of decisions, as previously described, we consider basically three possibilities: to cut the trees, delay trees cutting, and abandon project or convert land to another usage. Hence, we define a decision variable $D_{t}^{i}$ that may assume three values according to the decision taken at time $t$ and state (price index expectation) $i$.

\section{1, if trees are cut, \\ 2, if cutting is postponed and the investment maintained, \\ 3, if the project is abandoned or the land converted to another use,}

The inventory of wood is considered to be a deterministic process, following a known growth pattern according to the considered region, the time since last cut (or plantation), and the rotation. The evolution of the time since the first cut (or plantation) $x_{t}$ is modeled as:

$$
x_{t+1}= \begin{cases}2 & \text { if } D_{t}^{i}=1, \\ x_{t}+1 & \text { if } D_{t}=2,\end{cases}
$$

and initialized as $x_{1}=1$. In the second rotation $x_{t+1}$ is initialized as 2, rather than 1 , since the trees are already there and thus, do not need to be planted. If the decision is to abandon the project or convert land to another use then the project ends. 
Regarding the inventory of wood, we need two variables to represent it. One concerning the inventory of wood that is good for paper pulp production and another for the wood that does not meet paper pulp industrial requirements. Recall that, as explained before, the wood obtained from trees having up to 7 years of growth, as well as from trees with more than 16 years of growth, does not meet paper pulp industrial requirements. Let $t c_{\min }=8$ and $t c_{\max }=16 \mathrm{be}$, respectively, the minimum and maximum time from plantation (or first cut) for the trees to be suitable for paper production. Let $\operatorname{SQ}\left(\mathrm{x}_{t}, \mathrm{i}\right)$ and $\mathrm{CQ}\left(\mathrm{x}_{\mathrm{t}}, \mathrm{i}\right)$ be the inventory of wood that can be sold to paper pulp production and the inventory of wood that is extracted from cutting the trees, respectively. On one hand, if tree cutting occurs within 8 to 16 years of growth, then these two figures, obviously, have the same value. On the other hand, if trees are cut before reaching 8 years of growth or after 16 years of growth, then $\mathrm{SQ}$ is zero ${ }^{2}$ while $\mathrm{CQ}$ is positive.

$$
\begin{aligned}
& S Q\left(x_{t}, t\right)= \begin{cases}0, & \text { if } x_{t}<t c_{\text {min }} \text { or } x_{t}>t c_{\text {max }}, \\
Q_{1}\left(x_{t}\right), & \text { if } x_{t}=t, \\
Q_{2}\left(x_{t}\right), & \text { if } x_{t}<t,\end{cases} \\
& C Q\left(x_{t}, t\right)= \begin{cases}Q_{1}\left(x_{t}\right), & \text { if } x_{t}=t, \\
Q_{2}\left(x_{t}\right), & \text { if } x_{t}<t,\end{cases}
\end{aligned}
$$

where $Q_{1}\left(x_{t}\right)$ and $Q_{2}\left(x_{t}\right)$ are the quantities of wood extracted from cutting the trees which have been growing for $x_{t}$ years at rotation 1 and rotation 2, respectively.

\subsection{Dynamic programming model}

In each period, the forest investor must decide whether the forestry investment is going to be kept or not. Since both for project abandonment and land use conversion options only a lump sum is received, no subdivision is considered regarding these options. However, for the former case, the forest investor still has to make a decision regarding the timing of tree harvesting. The investor will choose either to harvest at the current period or to leave the trees there for the next period, whichever yields better expected cash flows.

Harvesting the trees yields the owner revenue from selling the wood but also involves costs $K$ incurred with cutting, peeling, and transporting the wood. Therefore, at period $t$, given the elapsed time since last cut or plantation $x_{t}$ and the

\footnotetext{
${ }^{2}$ Any other value, that could be obtained for the wood, can be used in our model.
} 


\section{OADVANCES IN MODELING AGRICULTURAL SYSTEMS}

price expectation index $i$, the net revenue $\pi$ obtained if the cutting option is exercised is given by

$$
\pi\left(x_{t}, i, t\right)=P_{t}^{i} \times S Q\left(x_{t}, t\right)-K \times C Q\left(x_{t}, t\right)
$$

As described before, in order to allow for earlier exercise, the valuation procedure begins at the last stage and works backwards to the initial moment. At the final lattice nodes, i.e., at the end of the project life $t=T$, all possible selling price values and elapsed time since last cut values are computed. For each of these terminal nodes the project value is then given by the largest of (i) the final revenue plus residual value if a harvesting decision is still possible and exercised or (ii) the residual value. Here, by residual value $R$ we mean the maximum between abandoned land value and land conversion value. The land conversion value is assumed to have no real appreciation or depreciation. Evidence shows that agricultural and forest land values have been stationary. However, in the empirical sections we perform some model sensitivity analysis to the value of $R$. It should be noticed that, after second harvest or at the end of the period of analysis if no second harvest takes place the project value is given by the residual value $R$. Furthermore, this value is the same both for the base and the extended problems, which is in accordance with the fact that no additional investment costs have been considered for latter problem.

$$
V\left(x_{T}, i, T\right)=\max \left\{\begin{array}{l}
\pi\left(x_{T}, i, T\right)+R \\
R
\end{array}\right.
$$

The project value at each intermediate lattice node is computed by performing a backward induction process. The project value at intermediate steps is used to compute the project value at previous steps by using risk neutral probabilities. The decision made at any period (and state variable) has implications not only on the cash flow of the current period but also on the expected cash flow of future periods. Therefore, the optimal project value is obtained by maximizing the sum of the current period's net revenue with the optimal continuation value considering all possible decisions. The optimal project value at period $t$, given the elapsed time since last cut or plantation $x_{t}$ and the price expectation index $i$, is then given by

$$
V\left(x_{t}, i, t\right)=\max _{D_{t}^{i}} \begin{cases}\pi\left(x_{t}, i, t\right)+\frac{p V\left(x_{t+1}, i+1, t+1\right)+(1-p) V\left(x_{t+1}, i-1, t+1\right)}{1+\mathrm{r}_{\mathrm{f}}} & \text { if } D_{t}=1, \\ R V\left(x_{t+1}, i+1, t+1\right)+(1-p) V\left(x_{t+1}, i-1, t+1\right) & \text { if } D_{t}=2, \\ R & \text { if } D_{t}=3,\end{cases}
$$

where $\pi\left(x_{t}, i, t\right)$ is the net revenue from the selling of the wood, $r_{f}$ is the real risk free interest rate, $p$ is the risk neutral probability of an upward movement in 
the binomial price, and $R$ is the largest of the abandonment value or conversion to another use value.

The estimated project net value is then given by $V(1,1,1) /\left(1+r_{f}\right)$ minus the initial investment ${ }^{3}$. Furthermore, the solution to this model also provides an optimal decision strategy for the forest manager.

In the following section the dynamic programming model given by equations (3) and (4) is empirically tested through the application to a case study of investment in eucalyptus for the paper pulp industry, in Portugal.

\section{Case study}

In this section, we start by giving a brief characterization of the Portuguese forest sector. Secondly, we describe the case study to which our model is to be applied, and end by presenting the results obtained.

\subsection{Brief characterization of the Portuguese forest sec-} tor

Portugal, due to its natural characteristics, possesses unique natural and ecological conditions for forestry production, which only recently has started to be methodologically and professionally managed. This fact is particularly true for high productivity forest species such as the eucalyptus globulous for the paper industry.

According to forest inventories (DGRF - Database 2001), forest and wooded land represent $37.7 \%$ of the Portuguese continental regions. Nowadays, the main species existent in Portuguese forests are pinus pinaster $(29.1 \%)$, cork oak $(21.3 \%)$, and eucalyptus $(20.1 \%)$, the latter being mainly represented by the eucalyptus globulous species.

The eucalyptus globulous, the main sub-species in our country and the one that possesses the best characteristics for paper production, is a fast growing tree. Originally biologically adapted to the poor soils of the Australian continent, in southern Europe, and Portugal in particular, this species grows very rapidly. Normally, the eucalyptus are cut with an age of 12 years and used to produce pulpwood, providing cellulose fibers that have remarkable qualities for the production of high quality paper. In what concerns ownership, the pulp industry manages ap-

${ }^{3}$ The initial investment is considered to be given by the land acquisition costs, the plantation costs, and the cost of a maintenance contract for the full length of the project. However, this contract does not include cutting, peeling, and transportation of the harvested wood, which account for the exercise price of the cutting option. 


\section{ADVANCES IN MODELING AGRICULTURAL SYSTEMS}

proximately $30 \%$ of the eucalyptus area in Portugal. The increase in the paper and pulpwood production translated into an increase in real terms of about $50 \%$ of the gross value added of the forestry sector, which reveals a much faster growth than the one observed for the rest of the Portuguese economy [7].

Forest and forest related industries are a key sector in the Portuguese economy, generating wealth and employment. The modernization of this sector can be a source of competitive advantage for the country, given the favorable ecological and natural conditions. Due to the development of the paper production industry and the natural characteristics of the species, eucalyptus globulous has shown to be a key player in the sector, with a huge wave of investment in the species in the last decades.

\subsection{Data and parameters}

The initial investment: plantation and maintenance costs

We assume that the investor contracts all expected operations to a specialized firm at the start of the investment and pays the contract in advance. The operations and their present value costs add up to 3212 euros per hectare, from which 1712 euros correspond to the plantation and the 2 rotations maintenance contract (which can last from 15 to 31 years, with 23 years expected duration), and 1500 euros correspond to the acquisition cost of 1 hectare of land. The details of how these values were obtained are given in Appendix A. Recall that, in this study two scenarios are considered. The base problem considers that the eucalyptus forest is owned by a forest investor, and that its wood is sold to pulp and paper companies. The extended problem considers that the eucalyptus forest is owned by the paper industry and that the wood is processed into white pulp, which is then sold. The two problems are included in order to distinguish outputs for different types of agents. Hence, the pulpwood productive capacity is considered to be present and its investment is disregarded and treated as a sunk cost, not relevant for undergoing investment projects.

Wood and white paper pulpwood prices

The price of wood in the base problem and the price of white paper pulpwood in the extended problem are assumed to follow a binomial stochastic process, as previously explained. We use 2002 prices: 45 euros per cubic meter of peeled eucalyptus wood; and 500 euros per cubic meter of white paper pulp [2]. The prices volatility was extracted from the time series of prices [12,7], considering constant prices of 2002 and using the consumer price index as deflator [15]. The extracted volatility corresponds to the volatility of returns of the three-years moving average of prices. This average was calculated in order to smooth the price series, as jumps in prices were periodical ( 3 year intervals between jumps). The 
price volatility measured by the standard deviation has been computed to be 0.0717 for wood and 0.1069 for white pulpwood.

Wood and white paper pulpwood quantities

In order to compute the quantities of available wood per ha of eucalyptus forest we have used the inventory model Globulus by Tomé, Ribeiro \& Soares [27]. We have considered wood quantities for the three main Portuguese regions in what concerns eucalyptus investment: north central coast (region 1), central coast (region 2), and river Tejo valley (region 3). For each region and rotation we consider different tree growth patterns. The average growth curve for the amount of wood in a hectare of eucalyptus forest land in each of the regions can be observed in Appendix B. In the extended problem, which uses pulpwood valuation, it has been considered that about 3.07 cubic meters of wood are required to produce 1 ton of white pulp, which corresponds to approximately 1.1 cubic meters of white pulp [27].

The exercise price for the cutting option $K$

The exercise price of the cutting option is given by the costs incurred in cutting the trees, peeling the wood, and transporting it to the factory. Considering constant prices of 2002, the total cost is estimated to be 22.5 euros per cubic meter of wood [2]. When considering the extended problem, which takes into account transformation into white pulp, the cost of this transformation must also be taken into consideration. The industrial processing cost is approximately 320 euros per ton of white pulpwood ${ }^{4}$ (200 euros of variable costs and 120 euros of fixed costs). The cost of cutting, peeling and transporting the wood necessary for a ton of white paper pulp is 69.14 euros. Therefore, a ton of white paper pulp costs 389.14 euros to transform. As 1 ton of white paper pulp corresponds to 1.1 cubic meters, the cost of processing 1 cubic meter of white paper pulp is then 353.76 euros [22].

The risk free interest rate $r_{f}$

As we are working with real prices from the year 2002, we have considered a real risk free interest rate of $3 \%$. This value was approximated through the observation of the Euro yield curve (average nominal risk free interest rate of 5\% for long term investments such as the eucalyptus) and the $2 \%$ expected inflation target in the Euro area (Eurostat).

${ }^{4}$ This value was obtained through the analysis of the operating costs of the paper pulpwood companies and their installed capacity, and also through inquiries to experts. 


\section{ADVANCES IN MODELING AGRICULTURAL SYSTEMS}

The abandonment and Conversion to another land use value $R$

In each time step, the investor possesses the option to abandon the investment project, putting the land aside and/or receiving the market price for agricultural and forest land.

In other situations, the investor may convert the land use into other activities, e.g., tourism, hunting, or real estate development. In this work, we consider both situations. We assume that demand may exist for the land as it is, or for the land to be converted to another use. Several possible values for the conversion value $R$ are considered, from the situation where no value is given to the land due to lack of demand, to situations of high conversion values that may arise, for example, due to real estate speculation.

\section{Results}

In this section, we specify the computational experiments conducted as well as the results obtained. All experiments have been performed using three regions in continental Portugal: 1 - north central coast, 2- central coast, and 3 - river Tejo valley, which present different productivity, as shown in Appendix B.

The results are divided into two sections, one regarding the dynamic programming model discussed in the previous section and another regarding the application of the harvesting strategies obtained to randomly generated data sets. In the first section, we report on the results obtained by applying the aforementioned dynamic programming model to the base and extended problems. In the second section, we present results regarding the implementation of the optimal strategies provided by the dynamic programming model to both the base and the extended problem. In order to do so, we randomly generate sets of price data, to which we apply these optimal strategies. The application of these strategies to the randomly generated data only considers the fact that price movements are upwards or downwards, disregarding the magnitude of the movement.

\section{$A-$ Results for the base and extended problems}

To start with, and in order to have a standard project value, we compute the value of the project considering that cuts are performed at years 12 and 23 respectively, the industry common practice. The price values used are the expected value of the price at years 12 and 23. Several possible values are considered for the land residual value. This valuation is in nature a net present value approach. The cut timing strategy considered has been observed to be the most common among eucalyptus forest managers.

The results, reported in Table 1, are computed, for the three above mentioned regions, as 


$$
\sum_{k=1}^{12} p_{k, 12} \frac{\pi(12, k, 12)}{\left(1+r_{f}\right)^{12}}+\sum_{k=1}^{23} p_{k, 23} \frac{\pi(12, k, 23)}{\left(1+r_{f}\right)^{23}}+\frac{R}{\left(1+r_{f}\right)^{23}},
$$

where $p_{k, 12}$ and $p_{k, 23}$ are the probabilities of having a price index $k$ at the twelfth and twenty third years, respectively and are computed as

$$
V\left(x_{t}, i, t\right)=\max _{D_{t}^{i}} \begin{cases}p^{t-1} & \text { if } k=1 \\ (1-p)^{t-1} & \text { if } k=t \\ (1-p) \cdot p_{k+1, t-1}+p \cdot p_{k-1, t-1} & \text { otherwise }\end{cases}
$$

\begin{tabular}{c|ccc|ccc}
$\begin{array}{c}\text { Residual } \\
\text { value }\end{array}$ & \multicolumn{3}{|c|}{ Base problem } & \multicolumn{3}{c}{ Extended problem } \\
& region & region & region & region & region & region \\
& 1 & 2 & 3 & 1 & 2 & 3 \\
\hline 0 & 11695 & 9705 & 6137 & 34605 & 28785 & 17958 \\
1000 & 12201 & 10212 & 6643 & 35111 & 29291 & 18464 \\
2000 & 12708 & 10719 & 7150 & 35618 & 29798 & 18971 \\
3000 & 13215 & 11225 & 7657 & 36125 & 30305 & 19478 \\
4000 & 13721 & 11732 & 8164 & 36632 & 30811 & 19985 \\
5000 & 14228 & 12239 & 8670 & 37138 & 31318 & 20491
\end{tabular}

Table 1. Common practice project value, for varying residual values.

Regarding the values obtained by our model, and in order to show that the postpone and abandonment/conversion options interact, we value the project considering (i) that only the harvesting and postponement options exist and (ii) that all options exist. Furthermore, the project is valued considering several land residual values $R$.

For the results presented in Table 2, where only the harvesting and postponement options exist, the residual value $R$ is only recovered at the end of the project. This happens, at time $T$ or either whenever the two possible cuts have already been performed or no further cutting is allowed.

\begin{tabular}{c|ccc|ccc}
$\begin{array}{c}\text { Residual } \\
\text { value }\end{array}$ & \multicolumn{3}{|c|}{ Base problem } & \multicolumn{3}{c}{ Extended problem } \\
& region & region & region & region & region & region \\
& 1 & 2 & 3 & 1 & 2 & 3 \\
\hline 0 & 15959 & 13084 & 8186 & 51295 & 42116 & 26030 \\
1000 & 16371 & 13496 & 8599 & 52114 & 42935 & 26849 \\
2000 & 16784 & 13909 & 9012 & 52934 & 43755 & 27667 \\
3000 & 17196 & 14322 & 9426 & 53753 & 44574 & 28488 \\
4000 & 17609 & 14735 & 9842 & 54573 & 45396 & 29308 \\
5000 & 18022 & 15149 & 10261 & 55393 & 46219 & 30128
\end{tabular}

Table 2. Real options project value, for varying residual values. 


\section{ADVANCES IN MODELING AGRICULTURAL SYSTEMS}

When considering all options the residual/conversion land value is obtained in the same conditions as above or whenever it is optimal to give up further harvesting. In the experiments performed, we have considered that the value to be recovered is the residual value $R$, since a better comparison with the results obtained when considering only the harvesting and postponement options, is possible. It should be noticed that, by doing so we are considering an abandonment option. In here, we only report one set of results, since the results obtained for cases (i) and (ii) were the same. Differences in the project value when considering all options began to appear only when there is an abnormal demand for the land, which appreciates its value to levels several times the considered acquisition value.

The differences in valuation between the standard NPV approach, typically used by the industry, and the options approaches here presented are clear. The real options approach, due to the consideration of the flexibility in the management of the forest, allows for much higher values. It provides a revenue increase that can go up to $36.46 \%$ for the base problem and up to $49.15 \%$ for the extended problem. It should be noticed that the increase decreases with the residual value, since the higher the residual value the smaller is the impact of the harvesting strategy on project value.

Another main conclusion that can be drawn is that the different sources of flexibility clearly interact. However, the difference in valuation considering the presence of all options and only the main cutting options is only relevant if considering very high residual values. This does not come as a surprise, since we consider that the residual value is a fixed value in time. Given that we are discounting future cash flows, then the residual present value decreases with project time horizon. Furthermore, we are not considering a real and specific land conversion value, which can often be much larger than the abandonment value.

Before comparing the results obtained for the base problem and the extended problem, let us recall what these problems represent. The base problem considers the situation where the forest is considered to be privately owned, and the eucalyptus wood is sold to paper industry companies. The extended problem, however, considers vertical integration of wood and paper production. The value added by the ownership of forest land being in the hands of the pulp industries (or the value added through vertical integration) can be estimated through the difference between the project values for the base and the extended problems, as given in Table 3. Recall that, for the extended problem, no additional investment costs are being considered, thus to the value added through vertical integration we still have to deduct the aforementioned investment costs.

\begin{tabular}{c|ccc|ccc}
$\begin{array}{c}\text { Residual } \\
\text { value }\end{array}$ & \multicolumn{2}{|c|}{ Harvest and postpone options } & \multicolumn{3}{c}{ All options } \\
& region & region & region & region & region & region \\
& 1 & 2 & 3 & 1 & 2 & 3 \\
\hline 0 & 35339 & 29035 & 17845 & 35339 & 29035 & 17844 \\
1000 & 35344 & 29040 & 17850 & 35345 & 29040 & 17851 \\
2000 & 35344 & 29040 & 17850 & 35345 & 29040 & 17851
\end{tabular}


MODEL FOR VALUING AN EUCALYPTUS INVESTMENT

\begin{tabular}{l|lll|lll}
3000 & 35355 & 29051 & 17861 & 35359 & 29056 & 17866 \\
4000 & 35344 & 29040 & 17850 & 35345 & 29040 & 17851 \\
5000 & 35366 & 29062 & 17872 & 35374 & 29070 & 17881
\end{tabular}

Table 3. Project value differences between base and extended problems, for varying residual values.

As it can be observed, the difference in project value is small and basically constant across the different residual values considered, that is, it almost does not depend on the residual value. Nevertheless, the value added through vertical integration seems to be extremely high, and justifies the observed direct and indirect investment of paper industry companies, out of their core business of paper pulp production, into producing the inputs themselves. Furthermore, as expected, the larger differences are observed for the most productive regions. However, care should be taken in drawing conclusions, since non-neglectful investments may be required for the vertical integration to take place. As these costs have not been accounted for in the results, the benefits of vertical integration are overestimated. This overestimation is however not as large as it might seem, as the residual value - the value of the firm at the end of the project - is the same for both problems.

\section{C-Applying the optimal strategies}

In order to evaluate the quality of the optimal strategy produced by our dynamic programming model, we apply the strategy provided by the model when considering all options, to randomly generated price data sets. The project value obtained in this way is then compared to the one that would be obtained by the common practice of harvesting after 12 years of growth. Five data sets have been randomly generated according to the characteristics given in Table 4 . The characteristics reported are relative to the price values used in the case study.

\begin{tabular}{c|ccc}
$\begin{array}{c}\text { Data } \\
\text { Set }\end{array}$ & minimum & $\begin{array}{r}\text { Price values } \\
\text { maximum }\end{array}$ & average \\
\hline 1 & $80 \%$ & $100 \%$ & $80 \%$ \\
2 & $100 \%$ & $100 \%$ & $90 \%$ \\
3 & $100 \%$ & $100 \%$ & $100 \%$ \\
4 & $100 \%$ & $100 \%$ & $110 \%$ \\
5 & $100 \%$ & $120 \%$ & $120 \%$
\end{tabular}

Table 4. Characteristics of the randomly generated data sets.

We report the project value obtained by applying the optimal strategies devised both for the base and the extended problems. These results are provided for the 5 randomly generated data set types. We also report on the common practice project value (CPV) obtained by performing the harvest at years 12 and 23, see tables 5 to 8 for different residual values.
Data
Region 1
Residual 0

| Region 2 $\quad$ Region 3


19DVANCES IN MODELING AGRICULTURAL SYSTEMS

\begin{tabular}{c|cc|cc|cc} 
set & value & CPV & value & CPV & value & CPV \\
\hline 1 & 33492 & 29619 & 27578 & 24271 & 16631 & 16476 \\
2 & 13813 & 12920 & 11548 & 10943 & 6060 & 6112 \\
3 & 48288 & 29479 & 39219 & 24500 & 26473 & 15363 \\
4 & 34748 & 48615 & 28550 & 40416 & 17540 & 25296 \\
5 & 46278 & 43898 & 37600 & 36559 & 25306 & 22645 \\
Average & 35324 & 32906 & 28899 & 27338 & 18402 & 17178
\end{tabular}

Table 5. Project value considering a residual of 0 for all regions when decision strategies are applied to specific data sets.

\begin{tabular}{c|cc|cc|cc}
\multicolumn{1}{c}{ Data } & \multicolumn{2}{|c}{ Region 1 } & \multicolumn{2}{c}{ Region 2 } & \multicolumn{2}{c}{ Region 3 } \\
set & value & CPV & value & CPV & value & CPV \\
\hline 1 & 33892 & 30126 & 27978 & 24778 & 17031 & 16983 \\
2 & 14213 & 13426 & 11948 & 11450 & 6460 & 6619 \\
3 & 48688 & 29986 & 39619 & 25006 & 26873 & 15869 \\
4 & 35148 & 49121 & 28950 & 40922 & 17940 & 25803 \\
5 & 46678 & 44404 & 38000 & 37066 & 25706 & 23151 \\
Average & 35724 & 33413 & 29299 & 27844 & 18802 & 17685
\end{tabular}

Table 6. Project value considering a residual of 1000 for all regions when decision strategies are applied to specific data sets.

\begin{tabular}{c|cc|cc|cc}
\multicolumn{1}{c}{ Data } & \multicolumn{2}{|c}{ Region 1 } & \multicolumn{2}{c}{ Region 2 } & \multicolumn{2}{c}{ Region 3 } \\
set & value & CPV & value & CPV & value & CPV \\
\hline 1 & 34692 & 31139 & 28778 & 25792 & 17831 & 17996 \\
2 & 15013 & 14440 & 12748 & 12463 & 7260 & 7632 \\
3 & 49488 & 30999 & 40419 & 26020 & 27673 & 16883 \\
4 & 35948 & 50135 & 29750 & 41936 & 18740 & 26816 \\
5 & 47478 & 45418 & 38800 & 38079 & 26506 & 24165 \\
Average & 36524 & 34426 & 30099 & 28858 & 19602 & 18698
\end{tabular}

Table 7. Project value considering a residual of 3000 for all regions when decision strategies are applied to specific data sets.

\begin{tabular}{c|cc|cc|cc} 
Data & \multicolumn{2}{|c}{ Region 1 } & \multicolumn{2}{c}{ Region 2 } & \multicolumn{2}{c}{ Region 3 } \\
set & value & CPV & value & CPV & value & CPV \\
\hline 1 & 35492 & 32153 & 29578 & 26805 & 18631 & 19009 \\
2 & 15813 & 15453 & 13548 & 13476 & 8060 & 8645 \\
3 & 50288 & 32013 & 41219 & 27033 & 28473 & 17896 \\
4 & 36748 & 51148 & 30550 & 42949 & 19540 & 27830 \\
5 & 48278 & 46431 & 39600 & 39093 & 27306 & 25178 \\
Average & 37324 & 35440 & 30899 & 29871 & 20402 & 19712
\end{tabular}


Table 8. Project value considering a residual of 5000 for all regions when decision strategies are applied to specific data sets.

As it can be seen, in the above situations the project has a larger value when computed using the real options approach. Region 1, the north central coast, is the most appropriate area in the country for eucalyptus and thus, the most productive. Results for the other two regions also provide the same conclusions.

It should be noticed that the harvesting decisions typically take place after sixteen years of growth for both rotations. This corresponds to the maximum time growth allowed. Thus, it can be concluded that the cutting option is exercised almost always at maturity, which allows for the investor to take advantage of the full tree growth. This fact is inconsistent with the common practice of most forest producers. The urge to cash in the value of their eucalyptus wood, due to high risk aversion, typically made at the 12 th year seems to be not optimal. A possible explanation may be that once the second cut is performed, then the project can be repeated and given the human life expectancy it may not make sense to wait longer than the minimum required time.

\section{Conclusions}

In this work, we address the valuation of an investment in eucalyptus forest land for the paper pulp industry by using real options theory. The modeling of the eucalyptus forest investment decisions using real options theory allows for valuation results more consistent with the normal positive investment outcomes than the ones obtained using traditional valuation techniques. The interpretation of the two possible tree cuts as two exercise interdependent call options on the wood allows for the introduction of managerial flexibility in the forest management process. The inclusion of the abandonment and conversion to another use options increases the closeness to the real decision process.

The evidence in this paper, through the application of the developed stochastic dynamic programming model to the eucalyptus investments in three Portuguese regions and for randomly generated situations, is consistent with the experts' warnings of the under-valuation performed by traditional discounted cash flow techniques. A rationale for the trend of vertical integration of paper pulp and wood production is also provided by the value difference between the two problems considered.

It is also shown that typical cutting time decisions by forest owners are not consistent with cash flow maximization. According to our model, cutting should be almost in all situations performed at the end of the time interval when wood is suitable for paper pulp production.

Acknowledgments

The authors would like to thank FCT for the financial support through scholarship BD/12610/03 and project POCI/MAT/61842/04. 
2ADVANCES IN MODELING AGRICULTURAL SYSTEMS

\section{Appendix A}

Initial investment: operation costs and present values

\begin{tabular}{|c|c|c|c|}
\hline \multirow[t]{2}{*}{ Year } & \multirow[t]{2}{*}{ Maintenance Operations } & \multicolumn{2}{|c|}{$\begin{array}{l}\text { Operation costs (eu- } \\
\text { ros) }\end{array}$} \\
\hline & & 2002 & $\begin{array}{l}\text { Present } \\
\text { value }\end{array}$ \\
\hline \multirow[t]{3}{*}{1} & Soil preparation and fertilization & & \\
\hline & Plantation & & \\
\hline & Infrastructures - Paths & 1100 & 1100 \\
\hline 1 & $\begin{array}{l}\text { Replantation }(10-15 \% \text { of planted } \\
\text { trees) }\end{array}$ & 60 & 60 \\
\hline 2 & Soil fertilization & 62.5 & 60.6 \\
\hline 3 & Soil cleaning (Milling cutter) & 90 & 84.8 \\
\hline \multirow[t]{2}{*}{4} & Soil fertilization & & \\
\hline & Infrastructures cleaning & 100 & 91.5 \\
\hline \multirow[t]{2}{*}{7} & Soil cleaning (Disc harrow) & & \\
\hline & Infrastructures cleaning & 100 & 83.7 \\
\hline 12 & Infrastructures cleaning & 10 & 7.2 \\
\hline 14 & Soil fertilization & 55 & 37.4 \\
\hline 15 & Road selection & 90 & 59.5 \\
\hline \multirow[t]{2}{*}{16} & Soil fertilization & & \\
\hline & Infrastructures cleaning & 100 & 64.1 \\
\hline \multirow[t]{2}{*}{19} & Soil cleaning (Disc harrow) & & \\
\hline & Infrastructures cleaning & 100 & 58.7 \\
\hline \multirow[t]{2}{*}{24} & Infrastructures cleaning & 10 & 5 \\
\hline & Value of plantation and maintenance contract & & 1712 \\
\hline
\end{tabular}




\section{Appendix B}

\begin{tabular}{c|ccc|ccc} 
& \multicolumn{3}{|c|}{ Rotation 1 } & \multicolumn{3}{c}{ Rotation 2 } \\
Year & Region & Region & Region & Region & Region & Region \\
& 1 & 2 & 3 & 1 & 2 & 3 \\
\hline 3 & 7.22 & 6.84 & 4.05 & 15.78 & 17.69 & 8.38 \\
3 & 18.09 & 16.06 & 10.29 & 15.78 & 17.69 & 8.38 \\
3 & 32.84 & 28.14 & 18.91 & 15.78 & 17.69 & 8.38 \\
3 & 50.16 & 42.06 & 29.14 & 15.78 & 17.69 & 8.38 \\
3 & 69.02 & 57.05 & 40.4 & 15.78 & 17.69 & 8.38 \\
3 & 88.67 & 72.59 & 52.23 & 15.78 & 17.69 & 8.38 \\
3 & 108.63 & 88.31 & 64.32 & 15.78 & 17.69 & 8.38 \\
3 & 128.54 & 103.97 & 76.46 & 15.78 & 17.69 & 8.38 \\
3 & 148.2 & 119.43 & 88.51 & 15.78 & 17.69 & 8.38 \\
3 & 167.47 & 134.59 & 100.38 & 15.78 & 17.69 & 8.38 \\
3 & 186.25 & 149.37 & 112 & 15.78 & 17.69 & 8.38 \\
3 & 204.49 & 163.76 & 123.33 & 15.78 & 17.69 & 8.38 \\
3 & 222.18 & 177.72 & 134.36 & 15.78 & 17.69 & 8.38
\end{tabular}

Table 10. Quantities of eucalyptus wood, in $m^{3}$ per ha .

\section{References}

[1] Abildtrup, J. \& Strange, N. (1999), 'The option value of non-contaminated forest watersheds', Forest Policy and Economics 1, 115-125.

[2] Aliança Florestal (2002), Technical Internal Report: www.alflorestal.pt.

[3] Arrow, K. \& Fisher, A. C. (1974), 'Environmental preservation, uncertainty and irreversibility', Quarterly Journal of Economics 88, 312-319.

[4] Bailey, W. (1991), 'Valuing agricultural firms: An examination of the contingent claims approach to pricing real assets', Journal of Economic Dynamics and Control 15, 771-791.

[5] Black, F. \& Scholes, M. (1973), 'The pricing of options and corporate liabilities', Journal of Political Economy 27, 637-654.

[6] Brennan, M. \& Schwartz, E. (1985), 'Evaluating natural resource investments', Journal of Business 58, 135-157.

[7] CELPA - (Associação da Indústria Papeleira), www.celpa.pt.

[8] Cox, J., Ross, S. \& Rubinstein, M. (1979), 'Option pricing: a simplified approach', Journal of Financial Economics 12, 229-263. 


\section{ADVANCES IN MODELING AGRICULTURAL SYSTEMS}

[9] DGRF - Database (2001), Inventário Florestal Nacional by Direcção Geral dos Recursos Florestais: www.dgf.min-agricultura.pt.

[10] Dixit, A. \& Pindyck, R. S. (1994), Investment under uncertainty, Princeton University Press, Princeton, New Jersey.

[11] Duku-Kaakyire, A. \& Nanang, D. M. (2004), 'Application of real options theory to forestry investment analysis', Forest Policy and Economics 6, $539-552$.

[12] FAO - (Food and Agricultural Organization of the United Nations), www.fao.org.

[13] Gjolberg, O. \& Guttornmsen, A. G. (2002), 'Real options in the forest: What if prices are mean reverting', Forest Policy and Economics 4, 13-20.

[14] Henry, C. (1974), 'Option values in the economics of irreplaceable assets', Review of Economic Studies 41, 89-104.

[15] INE - Infoline (2001), Instituto Nacional de Estatística: www.ine.pt.

[16] Insley, M. (2002), 'A real options approach to the valuation of a forestry investment', Journal of Environmental Economics and Management 44, 471-492.

[17] Insley, M. \& Rollins, K. (2005), 'On solving the multirotational timber harvesting problem with stochastic prices: a linear complementarity formulation', American Journal of Agricultural Economics 87, 735755.

[18] Malchow-Mollera, N., Strangeb, N. \& Thorsen, B. J. (2004), 'Real-options aspects of adjacency constraints', Forest Policy and Economics 6, 261270.

[19] Merton, R. C. (1973), 'An intertemporal capital asset pricing model', Econometrica 41, 867-887.

[20] Morck, R., Schwartz, E. \& Stangeland, D. (1989), 'The valuation of forestry resources under stochastic prices and inventories', Journal of Financial and Quantitative Analysis 24(4), 473-487.

[21] Pindyck, R. S. (1991), 'Irreversibility, uncertainty, and investment', Journal of Economic Literature 29(3), 1110-1148.

[22] Portucel Setúbal (2002), Technical Internal Report: www.portucelsoporcel.com.

[23] Reed, W. (1993), 'The decision to conserve or harvest old-growth forest', Ecological Economics 8, 45-49.

[24] Robichek, A. A. \& Myers, S. (1966), 'Conceptual problems in the use of riskadjusted discount rates', Journal of Finance 21, 727-730.

[25] Sharpe, W. F. (1964), 'Capital asset prices: A theory of market equilibrium under conditions of risk', Journal of Finance 19(3), 425-442.

[26] Thomson, T. A. (1992), 'Option pricing and timberlands land-use conversion option: comment', Land Economics 68, 462-469.

[27] Tomé, M., Ribeiro, F. \& Soares, P. (2001), O modelo glóbulus 2.1, Technical report, Grupo de Inventariação e Modelação de Recursos Naturais, Departamento de Engenharia Florestal, Instituto Superior de Agronomia, Universidade Técnica de Lisboa. 
[28] Wilmott, P. (1998), Derivatives, the Theory and Practice of Financial Engineering, Wiley, Chickester.

[29] Yin, R. (2001), 'Combining forest-level analysis with options valuation approach - a new framework for assessing forestry investment', Forest Science 47(4), 475-483.

[30] Zinkhan, F. (1991), 'Option pricing and timberlands land-use conversion option', Land Economics 67, 317-325. 